\title{
A estranha não morte da privatização neoliberal na Estratégia 2020 para a educação do Banco Mundial
}

\author{
SUSAN L. ROBERTSON \\ Universidade de Bristol
}

Tradução de Jeffrey Hoff Revisão técnica de Mário Luiz Neves de Azevedo

\section{INTRODUÇÃO}

Em 2012, o Grupo Banco Mundial (BM) comemora meio século de atuação no campo do desenvolvimento da educação (Jones, 2007).E, embora "[...] certamente tenha o maior prestígio e [...] seja o mais poderoso produtor de conhecimento sobre o desenvolvimento internacional" (Berger; Beeson, 1998, p. 487), para muitos observadores, os feitos do BM pela redução da pobreza, especialmente no último quarto de século, foram muito pouco expressivos. Além disso, desde os anos 1980, com a mudança para o "neoliberalismo" como paradigma ideológico que orienta o desenvolvimento, as políticas do $\mathrm{BM}$ têm tido consequências negativas para o crescimento econômico e a igualdade social no mundo. O setor da educação não foi exceção nessa mudança de paradigma e tampouco deixou de sofrer seus efeitos. Klees descreve as políticas neoliberais do BM para a educação como um "grande experimento" (2008, p. 312), envolvendo "[...] pagamento por serviços públicos, a privatização de mais atividades educacionais e uma conexão direta entre gerenciamento e financiamento da educação por rendimentos mensuráveis".

Essa política mista - comumente chamada de "Consenso de Washington" - "[...] foi atrativa pela simples ideia de que a globalização teria o poder de 
livrar nações da pobreza" (Rodrik, 2011, p. 164-165). Em meados dos anos 1990, entretanto, o Consenso de Washington foi largamente considerado uma "marca danificada", não apenas pela oposição ideológica que havia gerado, mas em virtude de crescentes evidências de que duas décadas de políticas de desenvolvimento neoliberal não teriam atenuado, e sim reforçado a pobreza e a desigualdade mundiais (ILO, 2004; Klees, 2008; Rodrik, 2011; Wade, 2004). A tentativa de encontrar um caminho para seguir em frente, ao promover a "boa governança" - conhecida como o "pós-Consenso de Washington"-, não foi o suficiente para afastar a crise, consequência inevitável da desregulação financeira. No ano de 2008, quando o mundo enfrentava sua pior crise financeira mundial desde os anos de 1930, o neoliberalismo como paradigma de desenvolvimento foi novamente posto em questão. De fato, alguns intelectuais chegaram a falar de uma nova ordem mundial "pós-neoliberal", enquanto o BM, de sua parte, prometeu a modernização do sistema multilateral e um "novo Grupo Banco Mundial". Teria o BM finalmente mudado de ideia a respeito do neoliberalismo e então buscado traçar uma nova trajetória de desenvolvimento para a década seguinte?

De acordo com Graham Harrison (2005), mudar de direção não é atitude nova para o BM. Voltando-se para a sua história a partir do pós-guerra, Harrison $(2001 ; 2005)$ argumenta que o que há de mais surpreendente a respeito do BM é a sua dificuldade em comprometer-se com suas próprias convicções. Ele nota certo padrão contínuo no desenrolar de movimentos, para frente e para trás - declara guerra àqueles estados que havia anteriormente financiado com otimismo, para em seguida fazer recuos táticos de políticas que havia antes promovido com grande zelo. Harrison avança no seu argumento:

Ao analisar todas essas mudanças de direção - com frequência deixadas sem justificativa pelo Banco -, fica a impressão de que é uma instituição inconsistente e reacionária, insegura a respeito de como se representar para o mundo exterior, enquanto ao mesmo tempo aplica consideráveis recursos para refutar ou assimilar parcialmente as críticas dos outros. (2001, p. 530)

Levando em conta esse histórico, era possível acreditar que o BM fosse, mesmo que minimamente, engajar-se num recuo tático do neoliberalismo. No entanto, apesar da crise que engolia os pilares da ideologia neoliberal nos Estados Unidos e no Reino Unido, se olharmos criticamente para o relatório Estratégia 2020 para a educação (Education strategy 2020) (World Bank, 2011) do BM - o foco deste artigo - a economia de livre mercado está viva e forte. No relatório do BM, intitulado Novo mundo, novo Grupo Banco Mundial: (I) diretrizes pós-crise (New world, new World Banking group: (I) post crisis directions) (World Bank, 2010), que enquadra as prioridades da Estratégia 2020 para a educação, enquanto falhas de regulação e supervisão são reconhecidas como presentes no coração da crise (World Bank, 2010, p. 4), o BM, não obstante, prossegue discutindo em favor de um maior papel para si na governança global, assim como defendendo um papel expandido para o setor privado de desenvolvimento. Paradoxalmente, em vez de 
afastar-se dessas políticas, como sugere Harrison, fica claro que o BM se propõe a lidar com os fracassos do neoliberalismo reinventando mais avançadas rodadas de intervenção neoliberal (Peck, 2010).

No presente artigo, investigo essa estranha "não morte do neoliberalismo" (Crouch, 2011) entre as prioridades das políticas do setor educacional do BM e suas implicações para a educação enquanto um bem da sociedade e um direito humano. Uma questão-chave diz respeito aos dois relatórios da estratégia do setor educacional, Estratégia para o setor educacional de 1999 (Education sector strategy) (World Bank, 1999) e Estratégia 2020 para a educação (Education strategy 2020) (World Bank,2011), utilizados para orientar as operações do BM na área. Para que se localize esses relatórios em meio a desenvolvimentos políticos e econômicos mais amplos, inicialmente faço alguns comentários introdutórios sobre o neoliberalismo como projeto político. Em seguida, abordo então o relatório Estratégia para o setor educacional de 1999, focando particularmente as maneiras como um setor privado expandido, juntamente com a Corporação Financeira Internacional (International Finance Corporation - IFC) (o braço investidor do setor privado do BM), é promovido como tendo o conhecimento e a capacidade para atuar num papel mais central na educação como um "mercado emergente". Num terceiro momento, mostro as maneiras como um pequeno grupo de empresários das políticas educacionais encaminhou e buscou materializar essa pauta para a educação sob a rubrica das parcerias público-privadas (PPP). Examino, assim, as evidências que esses empresários de políticas criam e usam para levar adiante seus argumentos e aponto para a natureza circunstancial dessas evidências. Em quarto lugar, mostro as maneiras com que essa pauta não apenas segue vigente, mas como se expande no relatório Estratégia 2020 para a educação. Isso se dá apesar do protagonismo do neoliberalismo na atual crise econômica mundial, do caráter tênue das evidências de que o setor privado é mais eficiente e dos investimentos questionáveis da IFC. Finalmente, reflito sobre o neoliberalismo enquanto projeto político e sobre o fato de que, apesar de seus fracassos visíveis, a menos por ora esses fracassos parecem inspirar rodadas mais avançadas de engenhosidade neoliberal no setor educacional.

\section{ENTRA EM CENA O NEOLIBERALISMO - ESTILO CHICAGO; SAI A REGULAÇÃO ESTATAL - E KEYNES}

Embora a maioria de nós conheça o perfil do neoliberalismo como um projeto hegemônico, há uma série de questões que são relevantes para este item. A primeira é a de que, para entender a importância da abertura da educação para o setor privado, precisamos antes olhar para o início dos anos 1970, para a crise do projeto de desenvolvimento capitalista do pós-guerra (um casamento entre liberalismo econômico e social-democracia) (Harvey, 2005; Hobsbawm, 1994) e a eventual introdução da economia de livre mercado como a mais difundida percepção de como se deviam organizar as sociedades. Contudo, realizar essa visão não era inevitável, e, portanto, tampouco o era seu deslocamento e finalização. A segunda questão é que a crise dos anos 1970 não foi apenas uma crise de ideias políticas. Foi também uma crise estrutural 
nas economias avançadas do Ocidente, como consequência da exaustão do modelo de desenvolvimento fordista do pós-guerra (Harvey, 2005).

Ideias sobre um livre mercado minimamente regulado haviam circulado dos anos 1930 em diante, mas seus defensores não conseguiram garantir um ponto de apoio nos grupos políticos e grupos de formadores de políticas. Ao contrário, o keynesianismo, ou uma economia gestada pelo Estado, dominava. Tampouco havia consenso entre os próprios neoliberais. À medida que os eventos se desdobravam, uma clara divisão emergia ao longo das décadas que se seguiram entre a chamada Escola de Chicago (eventualmente triunfante) e a posição ordoliberal de base europeia. Podemos ver o contraste entre essas diferenças num quadro geral que apresenta a economia liberal com mínima influência do Estado de um lado e um mercado socialmente inserido do outro. O que preservou a união entre os neoliberais, no entanto, foi o compartilhamento de uma utopia de mercado e um desgosto visceral pelo keynesianismo e pelo socialismo. Contudo, como aponta Peck (2010, p. 65), o fardo do neoliberalismo é que ele não pode viver nem com o Estado e nem sem ele. Entretanto, entre eles se divergia drasticamente sobre até que ponto se deveria permitir que chegasse a atuação do papel do Estado.

Em todo o caso, dos anos 1980 em diante, as ideias da Escola de Chicago, regida pelos economistas Friedrich von Hayek e Milton Friedman, vieram a dominar. Apropriadas pelas administrações de Thatcher e de Reagan, no Reino Unido e nos Estados Unidos, respectivamente, o neoliberalismo no estilo Chicago viria a afetar o "grande movimento para a direita" [referência ao artigo "The great moving right show", de Stuart Hall, 1979]. À medida que projetos se desenrolavam nos anos 1980, um conjunto de ideias despontou: o desfazer das políticas protecionistas do Estado para viabilizar uma movimentação financeira mais livre, da mesma forma que para $o$ comércio e o trabalho dentro das fronteiras nacionais (ação conhecida como "desregulação"); a implementação de políticas de competitividade entre os setores público e privado enquanto gerasse eficiência; a privatização de uma série de atividades antes estatais; uma redefinição da atividade estatal (envolvendo um processo duplo de descentralização e recentralização). O Estado passou de ajudante do crescimento econômico a principal obstáculo a bloqueá-lo, enquanto "[...] a divisão internacional do trabalho foi transformada de ameaça em salvação" (Rodrik, 2011, p. 163).

Entre os círculos de políticas e desenvolvimento, esse conjunto de ideias passou a ser conhecido como o "Consenso de Washington" (Williamson, 1993). Os mercados e a competição e o papel do setor privado em novas e antigas áreas de serviços, incluindo a educação (Ball, 2007), foram apresentados como "de interesse nacional", centrais para a competitividade na economia global, como meio de diminuir a pobreza e estancar a desaceleração do crescimento econômico, e como fundamentos para a construção de economias baseadas no conhecimento. Dos anos 1980 em diante, importantes agências internacionais, como o Grupo Banco Mundial (BM), o Fundo Monetário Internacional (FMI) e a Organização para a Cooperação e o Desenvolvimento Econômico (OCDE), atuaram num papel cada vez mais instrumental na promoção global das ideias de livre mercado da Escola de Chicago. Em países mais pobres, projetos políticos neoliberais - frequentemente chamados de "políticas numa 
mala" - foram levados adiante por meio das Políticas de Ajuste Estrutural (Structural Adjustment Policies - SAPs) do BM e do FMI (Samoff, 1994). No entanto, esse repertório de políticas (descentralização, privatização, pagamento por serviços públicos, financiamento comunitário) teve consequências devastadoras, não só na qualidade e oferta desses sistemas de educação, mas nas sociedades mais amplas das quais eles faziam parte (Bonal, 2002; Ilon, 1994; Klees, 2008).

Nos anos 1990, os evidentes fracassos do Consenso de Washington, em especial os níveis de crescimento econômico mundial consideravelmente mais baixos que ele presidiu, deixaram para os neoliberais uma difícil questão: como avançar sem repudiar o neoliberalismo enquanto projeto? O Consenso de Washington foi reabilitado com a retenção das suas características mais amplas enquanto se expandiu para incluir uma série de reformas adicionais com a rubrica da "boa governança": extensivas reformas na administração pública, PPPs, a eliminação de barreiras comerciais e uma nova leva de acordos no mercado internacional. O último desses quesitos, entretanto, veio a ficar de lado quando a recém-formada Organização Mundial do Comércio (OMC) encontrou, em 1995, grandes dificuldades para promover negociações que protegessem os interesses das economias desenvolvidas à custa das economias em desenvolvimento. A respeito da abertura da educação para negociações através da OMC como um setor de serviços global, esta também enfrentou grandes protestos organizados que questionavam a possibilidade de a educação tornar-se uma commodity à venda.

Esses contínuos movimentos progressivos, conflitos e refluxos da reestruturação neoliberal levam à minha terceira questão. Uma vez que a visão utópica central do neoliberalismo - de livre mercado e livre economia - é, em última instância, impossível de ser realizada, ela inevitavelmente se depara com o fracasso. Entretanto, como argumenta Peck, essa visão também abastece uma dinâmica progressiva, pois:

[...] na clareza pura da sua aparição ideológica, o livre mercado, que foi acompanhado de intermináveis frustrações a partir do inevitável fracasso para chegar a esse impreciso destino, confere, entretanto, um grau significativo de impulso para o projeto neoliberal. Ironicamente, o neoliberalismo possui uma dinâmica progressiva, em virtude exatamente do caráter inatingível de seu destino idealizado. $\mathrm{Na}$ prática, o neoliberalismo nunca foi uma liberalização "de uma vez por todas", uma evacuação do Estado. Em vez disso, foi associado a programas de reforma direcionada para o mercado, numa espécie de revolução permanente. (2010, p. 7, grifo do original)

Em outras palavras, projetos neoliberais, inclusive para a educação, tendem a "fracassar em sua realização" (idem, p. 6). Essas rodadas de intervenção neoliberal, de "des-" "re-regulação", de fluxos, refluxos e contracorrentes é que criam os mundos do neoliberalismo realmente existente. Além disso, eles

[...] não são espaços imaculados de razão de mercado e ordem constitucional; eles são lugares institucionalmente desordenados, marcados por sistemas de governo experimentais e falhos, acúmulos de resquícios de problemas sociais e de fracassos de mercado em série. (idem, p. 31) 
Nas seções a seguir, veremos essas dinâmicas em ação na presente reinvenção do projeto de livre mercado do BM em meio ao setor educacional e na coleção de experimentos referente a diferentes projetos de privatização.

\section{LOCALIZANDO O RELATÓRIO ESTRATÉGIA PARA O SETOR EDUCACIONAL DE 1999}

É diante desse panorama de um esforço comum para manter o falho Consenso de Washington em curso, em meio à sua reformulação e renovação e da tentativa das economias desenvolvidas em avançar com um novo modelo econômico baseado num setor de serviços globalizados, que podemos então localizar o Estratégia para o setor educacional de 1999, o relatório do BM sobre as estratégias para a educação. Esse relatório é um documento de prospectiva que tem o papel crucial de orientar os investimentos em longo prazo do BM no setor da educação. Nesse caso, o Estratégia para o setor educacional de 1999 é o quarto relatório em 30 anos (os outros foram apresentados em 1970, 1975 e 1980), com 20 anos entre o terceiro e o quarto. Esse intervalo de 20 anos leva a crer que a ampla trajetória das políticas para o setor educacional do $\mathrm{BM}$, ao longo daqueles anos, não mudara significativamente até o fim dos anos 1990.

Apesar das dificuldades que o BM encontrava com suas políticas obstinadas de livre mercado, o relatório confiantemente afirma que as economias de mercado naquele momento dominavam a economia mundial, respondendo por mais de $80 \%$ da população mundial (World Bank, 1999, p. 11).Uma "economia centralmente planejada do passado" (apresentada como tendo "mais certezas, porém menos oportunidades") (idem, ibidem), quando comparada a um sistema de mercado dinâmico, deixa pouca dúvida de qual era preferível. No entanto, o relatório encoraja o seu leitor a suspender julgamentos sobre o ancoramento moral dessa sociedade de mercado, que é regida pela busca incansável por "margens de lucro finíssimas" e "margens de lucro 'pegar ou largar" (idem, ibidem). Em vez disso, a educação e os educadores são convidados ao "palco principal", para serem os meios pelos quais o futuro reserva vitória ou derrota para "indivíduos, comunidades e nações" (idem, ibidem). Mesmo que possa haver um jogo mais humano que esse, essa possibilidade não é levada em conta. Em vez disso, o relatório oferece apoio total a esse projeto político renovado, garantindo que governos estariam tornando-se menos os provedores de bens e serviços e mais os facilitadores e reguladores da atividade econômica. O desafio para o setor da educação também está claro: como criar aprendizes que sejam, por um lado, empreendedores, ágeis e dispostos a aceitar riscos, e, por outro lado, que sejam engajados no setor privado num panorama maior das atividades educacionais (tais como treinamento no trabalho, publicações, iniciativas tecnológicas, provisões educacionais).

O relatório do $\mathrm{BM}$, aparentemente consciente de que fortes alegações a respeito da privatização na educação seriam motivo de controvérsia, introduz o texto apontando que: "[...] a educação, na maioria dos países, é tanto financiada quanto fornecida pela esfera pública” (1999, p. 34), mas “[...] não há razão a priori para que toda a educação seja fornecida, financiada e administrada pelo setor público"(idem, ibidem). E continua: 
[...] há argumentos a favor de (1) encorajar seletivamente a administração e/ou a propriedade de instituições [educativas] por ONGs, comunidades de grupos religiosos e empresários, (2) de permitir que estudantes e seus pais escolham entre diferentes opções e (3) de exigir algum nível de financiamento privado após os níveis básicos. (1999, p. 35)

O relatório então passa a legitimar a adoção de um papel maior para o setor privado, expondo uma série de justificativas alinhadas com o mandato do BM, supostamente de caráter pró-redução da pobreza. Por exemplo: um setor privado maior estenderia oportunidades educacionais para estudantes mais pobres; financiamento privado expandiria o número de vagas disponíveis - especialmente nos níveis secundário e terciário -; os recursos públicos ficariam então liberados para os mais pobres; famílias passariam a ter escolhas além do setor público; o setor privado seria mais eficiente do que o setor público, enquanto a qualidade seria mantida a um custo unitário mais baixo; o setor privado aumentaria o potencial de inovação (World Bank, 1999, p. 28-29). Essas alegações demonstram um engajamento limitado, ou a compreensão limitada, com/de uma evidência mais ampla que havia sido gerada pelos sistemas nacionais de educação, voltados então para políticas de escolha (Gewirtz; Ball; Bowe, 1995) para novas formas de financiamento - particularmente de infraestruturas para a educação (Hatcher, 2006) e comercialização incipiente (Molnar, 2006). Em vez disso, o BM seguiu chamando por projetos financiados e também apoiados por ele, tais como um projeto de educação primária na República Dominicana, usando os famosos sistemas de voucher de Milton Friedman, bolsas de estudo para meninas, assim permitindo que frequentassem escolas privadas, e o desenvolvimento do setor privado na educação na Mauritânia e em Burkina Faso.

O projeto mais ambicioso, considerando a expansão dos novos engajamentos do BM com o setor privado, deve-se à constatação do potencial de expansão da IFC em seu papel na educação. A IFC tem a tarefa, distinta dos outros quatro ramos do Grupo BM, de apoiar o setor privado naquilo que ela descreve como "mercados emergentes”. A IFC foi fundada como um órgão separado do BM em 1956, quando governos que eram membros preocupavam-se com o fato de que empresários privados não estavam sendo efetivamente apoiados por agências multilaterais de empréstimo. A IFC também nasceu da crença de que o desenvolvimento econômico (e, portanto, a amenização da pobreza) dependia de um robusto setor privado. De acordo com o relatório Estratégia para o setor educacional de 1999, a especialidade da IFC em "[...] compreender os atuais e potenciais papéis do envolvimento do setor privado na educação" (World Bank, 1999, p. 28) significava que o órgão seria então capaz de:

[...] executar um papel no futuro desenvolvimento e abastecimento daquele segmento privado para o mercado da educação que expande oportunidades educacionais para estudantes de baixa renda. [...] Quanto mais as famílias abastadas pagarem pela educação (como fazem ao escolher a educação privada), mais o governo poderá usar seus recursos para os pobres. (idem, ibidem) 
Em outras palavras, financiar os abastados - de acordo com esse argumento - beneficiaria os pobres. Para avançar com seus esforços em abrir a educação como um setor de investimento, o relatório propôs o contínuo apoio ao EdInvest, lançado um ano antes (1998); um empreendimento conjunto entre a firma de educação sem fins lucrativos alocada no Reino Unido, o Centro para Professores Britânicos (Centre for British Teachers) (CfBT), e a IFC, como um portal de informação para investimentos globais no setor de educação.

Como levar em frente tal programa diante de uma considerável hostilidade para com a agenda de privatizações do BM que o Consenso de Washington havia arquitetado? A solução foi a ideia de parcerias, em particular as PPPs, previstas no relatório. Argumentando que "o trabalho de fortalecer a educação é muito grande para que qualquer instituição o faça sozinha” (World Bank, 1999, p. 18), as parcerias eram um meio de amenizar o estrago feito por formas anteriores de privatização e ao mesmo tempo não abandoná-las. Acima de tudo, parcerias permitiam múltiplos enquadramentos, interesses e objetivos a serem realizados (Newman, 2001, p. 107). A ideia das parcerias, portanto, era uma útil plataforma para que o BM continuasse avançando com seu plano de privatizar a educação. As PPPs não apenas uniram diferentes atores e, portanto, diferentes setores interessados e tipos de habilidades como elas ajudaram na corretagem ["broker in"], em vez de mitigação ou mediação da privatização na e da educação.

Esse relatório coincide, portanto, com um arsenal mais amplo de estratégias sendo levadas adiante pelas economias desenvolvidas e por agências multilaterais voltadas para a criação de competitivas economias de serviço baseadas no conhecimento que incluísse o setor em expansão de serviços da educação. Estas compreendem: trazer atores privados para a administração da educação sob o pretexto de que geravam maior eficiência do que os do setor público; abrir o setor da educação a regras de mercado globais; e a promoção do comércio (em vez de auxílio) na educação como a base para construção e entrega no acesso e na qualidade da educação (Robertson; Bonal; Dale, 2002).

Somadas, essas prioridades do relatório Estratégia para o setor educacional de 1999 ampliam para novas áreas as atividades do BM com o setor privado - para além das anuidades e das escolas particulares (Klees, 2002, p. 463). Oferecendo uma avaliação desse relatório, Klees (2002) argumenta que, apesar do ponto de vista promissor ("Educação de qualidade para todos"), um exame mais minucioso revelou não apenas pouca mudança de fato, mas também que o relatório está cheio de "[...] suposições não estudadas, fatos questionáveis e ideologia substituindo informação" (idem, p. 451). A avaliação de Klees do relatório aponta para claras continuidades na posição do BM sobre a educação em relação ao já ultrapassado Consenso de Washington. Mas subestima até que ponto a agenda de privatização do BM foi estrategicamente promovida para incluir novos atores com o Grupo BM e um pacote remodelado de ideias de livre mercado reformando o fornecimento da educação. 


\section{A CORRETAGEM NA PRIVATIZAÇÃO POR MEIO DAS PPPS: OS EMPRESÁRIOS DAS POLÍTICAS GLOBAIS PARA A EDUCAÇÃO}

É tentador pensar no neoliberalismo como uma arquitetura reguladora global imposta de cima para baixo. No entanto, como todos projetos políticos, o neoliberalismo requer um trabalho contínuo por meio de atores socialmente situados. Esses atores são os corretores de mitos, os mediadores de projetos e os criadores de novos espaços de neoliberalismo. Nesta seção, quero agora focar a estratégia de privatização - as PPPs mencionada brevemente no relatório Estratégia para o setor educacional de 1999 no item "Parcerias", mas que já ganhou vida, direção e solidez. Esse trabalho de corretagem feito pelos empresários das políticas da educação evidencia as maneiras como o neoliberalismo não apenas é vivido, mas é um projeto construído por uma rede de atores localizados em meio ao BM e para além dele.

Os corretores do projeto de privatização do BM, por meio das PPPs na educação, são uma pequena rede de empresários das políticas e especialistas em educação localizados nos interstícios de uma seleta gama de organizações internacionais, empresas internacionais de consultoria educacional e universidades globalizadas que têm sido responsáveis por promover a ideia das PPPs (Verger, 2012). Nos anos de 1990, representantes dessas organizações se encontraram no Grupo Temático Economias da Educação do $\mathrm{BM}$ e fundaram uma linha de pesquisa e discussão sobre formas privadas e alternativas para o fornecimento da educação, inicialmente focando a África subsaariana. Começaram a pensar sobre parcerias na educação como uma evolução e a solução para a hostilidade que a agenda de privatizações enfrentava. Como constata Crouch:

Uma extrema abordagem neoliberal dos serviços públicos faria com que estes se movessem inteiramente na direção do mercado, com consumidores pagando por si e o governo desempenhando papel nenhum. Isto se provou impossível, principalmente por razões democráticas: a maioria dos eleitores não apoiaria a abolição dos serviços públicos estabelecidos durante o auge do sufrágio universal. (2011,p. 95)

Em 2001, a IFC lançou um manual sobre as PPPs na educação. Os principais autores dessa colaboração foram Normal LaRocque, então diretor da Anderson Consulting Company, na Nova Zelândia, James Tooley, professor de políticas da educação no Reino Unido, e Michael Latham, conselheiro de educação para o CfBT Education Services, juntamente com Harry Patrinos, economista sênior da educação do $\mathrm{BM}$. A rede é estreita em escopo, mas muito coesa e pode ser mais bem descrita como uma pequena comunidade epistêmica que compartilha um compromisso comum com as ideias da Escola de Chicago, assim como é informada por um pequeno grupo de economistas da educação, em sua maioria de base estadunidense. Esse grupo é crucial para promover a agenda das PPPs para a educação de forma mais global; eles estão também por trás das mais conhecidas publicações, relatórios sobre políticas e kits de mecanismos sobre PPPs que culminaram no amplamente disseminado relatório do BM, O papel e impacto das parcerias público-privadas na educação, divulgado em 2009 (The role and impact of public-private partnerships in education) (Patrinos et al., 2009). A rede 
vem organizando uma série de eventos em que as PPPs são discutidas entre criadores de políticas, agências doadoras, com a equipe de organizações internacionais e entre seletos grupos acadêmicos. Seus membros escrevem e falam sobre as iniciativas uns dos outros (publicações, seminários, cursos, entre outros).

Uma suposição central feita por essa rede de políticas é a de que “[...] a educação é um bem de consumo e o estudante é o principal consumidor por intermédio de seus pais" (World Bank, 2001, p. 1). O que segue a partir dessa suposição é que, para que os pais (e estudantes) possam escolher, o setor da educação precisa ser organizado de modo que opere de acordo com a lógica de um livre mercado. Isso envolve informação sobre a natureza da oferta de educação do provedor, incluindo sua qualidade; uma série de incentivos que garantam o tipo certo de comportamento e performance; garantias regulamentadas que protejam os interesses dos investidores privados; competição entre provedores; e um sistema de avaliação capaz de dar retornos para o sistema de informações, criando assim um círculo virtuoso. Um círculo virtuoso é criado também entre os objetivos do BM em relação ao que as PPPs deveriam conseguir realizar (acesso, qualidade, custo e superação de desigualdades), a forma como diferentes tipos de PPPs podem afetar resultados educacionais e o uso de evidência empírica - muito da qual é financiada pelo BM como parte de seus estudos de impacto ou que provém de um grupo seleto de economistas da educação.

As PPPs têm sido o perfeito guarda-chuva, pois, enquanto o fornecimento de educação opera de acordo com princípios do livre mercado (competição, eficiência etc.), o Estado garante um estimulante ambiente de políticas e, o mais importante, financiamento. Assim observam Harry Patrinos et al. (2009, p. 1), funcionário-chave do BM:

[...] o governo guia as políticas e providencia financiamento, enquanto o setor privado fornece os serviços educacionais aos estudantes. Particularmente, os governos contratam provedores privados para proporcionar um serviço específico em quantidade e qualidade estabelecidas, a um preço combinado, por um período específico de tempo. Esses contratos envolvem recompensas e sanções das quais o setor privado compartilha o risco financeiro na entrega de serviços públicos.

E, como observa Crouch, pouco se fala sobre o fato de que serviços públicos universais, financiados pelo governo em vez de por escolha individual, oferecem mercados maravilhosamente seguros para aquelas empresas que se especializam em contratos de negócios públicos. Ele aponta que "[... ] o neoliberalismo parte grandemente do legado político e econômico do liberalismo em não ver problema algum em uma relação próxima entre empresa e Estado, considerando que a influência corra de empresa para Estado, e não vice-versa" (2011, p. 95). Ele está certo. Em países como o Reino Unido e os Estados Unidos, onde a educação faz parte do contrato Estado-cidadão, inversões ao ponto de o mercado angariar as posições do Estado provaram-se impossíveis. Em vez disso, uma nova posição emergiu adequando-se ao setor privado: um setor educacional financiado pelo público e fornecido pelo privado, através das PPPs. A pergunta sobre como o Estado regula atores privados no setor educacional, particulamente quando os atores privados escondem-se atrás de leis de 
"sensibilidade comercial", é uma questão importante e sem solução evidente. Mas uma questão igualmente importante é como o Estado administra as contradições cada vez mais profundas entre a educação enquanto direito humano, bem público, commodity vendável e mecanismo de coesão social, e a crise da regulação que agora toma conta da economia política mundial.

\section{CRISE, MODERNIZAÇÃO DO MULTILATERALISMO E O RELATÓRIO ESTRATÉGIA 2020 PARA A EDUCAÇÃO}

Embora a crise financeira mundial tenha começado a emergir bem antes que atraísse a atenção em 2007-2008, foi o ano de 2008 que ficou marcado como o momento em que esta se irrompeu. Jessop comenta que:

[...] a crise mundial é produto da interação de ao menos cinco processos: as crises mundiais do meio ambiente, de combustível, de água e alimentos; o declínio da hegemonia dos Estados Unidos, e seu domínio e credibilidade na ordem geopolítica pós-Guerra Fria; a crise de uma economia mundial organizada à sombra de uma neoliberalização contínua; uma série de crises estruturais ou de ramo em setores importantes (tais como o automobilístico e o da agricultura); e a crise dos regimes predominantemente financeiros de acumulação. (2011, p. 17)

Embora a crise tenha passado por diferentes estágios e se alastrado de forma desigual, o interesse aqui é se, como e em quais caminhos a crise desestabilizou o comprometimento do BM com as políticas de desenvolvimento da educação que têm sido orientadas pelo liberalismo de mercado, como mostrei, desde a década de 1980. Nos apontamentos iniciais do seu Novo mundo, novo Grupo Banco Mundial: (I) diretrizes pós-crise, redigido em abril de 2010, o BM está confiante de que o pior da crise já passou, mas acredita que novos esforços são necessários para que se caminhe para frente nessa nova ordem mundial. E, enquanto aponta que "falhas na regulação fiscal estão no centro do fracasso financeiro" e que "um governo efetivo"(p.4) é essencial, estão ausentes no relatório menções ao seu próprio papel em promover políticas que busquem limitar a regulação estatal. Em vez disso, o relatório convoca um papel expandido do Grupo BM fundamentando-se naquilo que chama de "modernização multilateral", e um papel central para o setor privado através de mecanismos como as PPPs, com o fim de suprir as necessidades dos mais pobres. No entanto, sua própria visão do que deve ser feito continua a ser formada por uma agenda que prevê menos regulação e não mais como fundamento para a competitividade. Assim constata:

Criar oportunidades para o crescimento do setor privado será crucial, principalmente quando se reduzem os pacotes de incentivo. Um setor privado empresarial pujante será exigido para sustentar o crescimento. Isso envolverá políticas, apoio técnico e operacional para uma agenda de ampla competitividade, de modo que elimine barreiras e promova oportunidades. (World Bank, 2010, p. 17) 
É esse conjunto de prioridades que molda o relatório do BM, o Estratégia 2020 para a educação, divulgado em abril de 2011. Argumentando que uma nova estratégia é essencial para ajudar na realização de sua meta para a educação - de garantir aprendizado de modo que forneça conhecimento de alta qualidade como base para o desenvolvimento econômico -, o BM considera tanto o importante papel dos governos (p. 3), por um lado, quanto um crescente papel da IFC no desenvolvimento da educação, por outro lado (p. 31). Ao argumentar que há fortes razões para a promoção da educação pelo governo, incluindo correções pelo fracasso do mercado em investir suficientemente na educação, e garantias de acesso àqueles que não podem pagar por ela (p. 3), o BM parece reconhecer os limites do mercado como modelo para o desenvolvimento da educação. Entretanto, também promove implicitamente a percepção de que o Estado fornece uma rede de segurança para aqueles com recursos insuficientes para participar do setor privado.

Uma inovação bastante significativa presente no relatório é a forte perspectiva em relação à "re-regulação" do setor da educação naquilo que se tem chamado de "ressetorialização da educação" (Robertson, 2011). Ao redefinir-se o termo "sistema de educação" para que inclua um espectro mais amplo de atores - de "governos nacionais e locais até provedores privados de educação, indivíduos e suas famílias, comunidades e organizações não lucrativas e lucrativas"(World Bank,2011) - a porta fica efetivamente aberta ao setor privado de maneira sistemática.

O apoio cada vez mais forte à privatização da educação fica também evidente no papel expandido designado à IFC. Assim é colocado:

O principal foco da estratégia da IFC para a educação é proporcionar financiamento para maiores provedores da rede que tenham a habilidade para investir além das fronteiras e descer às camadas do mercado popular para alcançar populações mais pobres; financiando a educação para empreendimentos pequenos e médios que tipicamente miram nas populações pobres e para estudantes por meio de bancos parceiros; e serviços de consultoria para empresas que sustetem a qualidade da educação e para bancos que garantam empréstimos responsáveis para o setor. (idem, p. 16)

Apesar dessas promessas de desenvolvimento em prol dos mais pobres, a IFC tem sido alvo de consideráveis críticas em virtude de seu fracasso em abordar as necessidades dos mais pobres. Isso então levanta a questão de qual o valor que ela agrega, especialmente, já que muitos dos projetos financiados pela IFC não levam em conta, na sua configuração, dimensões de pobreza e redistribuição. O Projeto Bretton Woods (2010, p. 3), organização de monitoramento sediada em Londres, que fiscaliza as ações e os desenvolvimentos do BM, discute como países de baixa renda estão preocupados que o apoio da IFC vá principalmente para poucos e grandes projetos e investidores transnacionais, nos quais a necessidade de financiamento é menor e possíveis benefícios de desenvolvimento são menores, sendo que em países mais pobres são necessários empreendimentos em escalas pequenas e médias. Eles também apontam que a responsabilização e a transparência são pontos fracos do trabalho do setor privado do BM 
e, acima de tudo, entre seus investimentos em expansão por meio de intermediários financeiros. O Independent Evaluation Group (IEG), o grupo de avaliação interna do $\mathrm{BM}$, levantou críticas similares sobre a IFC e seu fracasso no alcance dos muito pobres. Ambos levados em conta, podemos perceber que na mais recente Estratégia 2020 para a educação do BM, longe de reavaliar as privatizações neoliberais, a crise criou uma janela de oportunidades para uma expansão dessa agenda. Como Colin Crouch (2011), somos encorajados a perguntar sobre a estranha não morte do neoliberalismo.

\section{A ESTRANHA NÃO MORTE DA PRIVATIZAÇÃO NAS POLÍTICAS PARA A EDUCAÇÃO DO BM}

Tenho argumentado que o neoliberalismo, enquanto projeto político, apesar de seus evidentes fracassos no setor de desenvolvimento da educação, ao menos por ora parece incentivar novas levas de invenção neoliberal. Compreender como este vem a ser o caso e por que, apesar da crise global atual, o neoliberalismo está vivo e bem presente nas prioridades da educação para o BM é importante para se pensar sobre "o que deve ser feito". Como comenta Peck, o neoliberalismo demonstra certo nível de "persistência reprodutiva" (2010, p. 28), em parte isso é em virtude de sua capacidade de reinventar-se e pelos relacionamentos entre espaços exercitados no neoliberalismo, que continua sendo inserido num alcance de dinâmicas extralocais, transnacionais e que atravessam escalas ["cross-scalar"]. Em outras palavras, como elaborarei brevemente, projetos de educação neoliberais têm sido promovidos em territórios nacionais e espaços regionais que em troca reforçam o impulso e a direção das políticas para privatizar a educação. Isso é verdade considerando a persistência do $\mathrm{BM}$ com o neoliberalismo como paradigma. No que diz respeito à forma, em minha análise dos contínuos engajamentos com a privatização na/da agenda da educação aponto para duas amplas dimensões: uma é a estratégica e a outra é a estrutural.

Estrategicamente, podemos ver como ao longo do tempo o BM usou contínuas crises políticas e econômicas fazendo com que seguisse reinventando sua agenda de privatização da educação. Podemos ver uma série de estratégias e táticas diferentes sendo promovidas, cada qual acionada por uma crise. Inicialmente, podemos ver uma mudança do Consenso de Washington privilegiando o pagamento de serviços públicos e as escolas privadas para a posterior promoção de PPPs sob um neoliberalismo reinventado pós-Consenso de Washington (embora as economias de livre mercado mantenham-se como a lógica dominante guiando a provisão privada e o financiamento estatal), para a colocação mais recente da Estratégia 2020 para a educação, que redefine o sentido de um sistema de educação para que agora inclua, e anexe, o setor privado (lucrativo ou não) como ator-chave por dentro, e não por fora, do sistema de educação. Cada movimento para frente expandiu o âmbito e a agenda do BM, em vez de restringi-lo.

Em segundo lugar, ao empurrar a agenda de privatização da educação na direção de um órgão menos conhecido de seu grupo, a IFC, o BM empregou a tática da "troca de fórum" [“forum-shifting"] (Sell, 2009). Refletindo sobre as diferentes maneiras com que a agenda da propriedade intelectual foi taticamente promovida 
por meio de diferentes agências da Organização das Nações Unidas (ONU), incluindo a OMC, Susan Sell $(2009$, p. 1) percebe que

O termo "troca de fórum" pode referir-se a diversas dinâmicas distintas, sendo todas elas projetadas para produzir resultados desejados a partir de uma virada do jogo. Partidos podem mover uma agenda de um fórum para o outro, sair de um fórum inteiramente (e.g. os Estados Unidos saindo da UNESCO nos anos 1980), ou buscar agendas simultaneamente em múltiplos fóruns. De acordo com Peter Drahos, "trocar de fóruns significa que algumas negociações nunca terminam de fato".

De maneira similar, para o BM, a "troca de fórum" gera um novo espaço e introduz um novo ar fresco para a controversa agenda da privatização da educação; proporciona acesso a novos recursos, mobiliza novos tipos de habilidades, legitima sua atividade através do olhar para a educação como um "mercado emergente" alinhado com os objetivos da IFC, e ainda assim consegue permanecer menos visível, já que a IFC não é tão conhecida. De fato, a maioria dos observadores das políticas do BM para a educação tende a olhar para as atividades do Banco Internacional para Reconstrução e Desenvolvimento (BIRD) como o espaço em que se dão as políticas e programações da educação, sem considerar também a IFC.

O BM administra o conhecimento de uma maneira bastante tática. Primeiro, emprega estrategicamente o que chamo de "ventriloquismo do conhecimento"- ou o que seria um esforço para criar um círculo virtuoso entre políticas-pesquisa-evidência, consecutivamente. Quando desenvolve políticas acerca do papel do setor privado na educação, o BM tende a extrair evidências de um menu de estudos bastante estreito: ou aqueles comissionados e financiados por ele, ou a partir de trabalhos orientados pelos seus próprios pequenos círculos de empresários de políticas da educação e economistas da educação. Ao limitar o que poderia contar como evidência para as políticas, acaba limitando os possíveis desafios que essa evidência representa para contínuos enquadramentos políticos e construções de políticas e, portanto, para o neoliberalismo como um paradigma da organização. Segundo, amplia a evidência que apoia sua posição ideológica, de um lado, e alonga as partes específicas da evidência, do outro. Por exemplo: o contínuo uso, pelo BM, da análise do economista da educação Ludger Wossmann sobre os dados do [Programa para Estudantes Internacionais] PISA da Organização para a Cooperação e Desenvolvimento Econômico (OCDE) (Patrinos et al., 2009) e a performance de estudantes das escolas privadas são usados repetidas vezes para justificar a expansão da educação privada. Mas há muitos tipos de "educação privada", entre os quais alguns claramente não baseados nas mesmas formas de lógica (competição/eficiência) que o BM sugere que gerariam níveis mais altos de performance estudantil. $\mathrm{O}$ círculo se fecha ainda mais quando o $\mathrm{BM}$ tende a generalizar valendo-se de partes limitadas de evidências, tira certos exemplos de questão ou ameniza diferenças entre descobertas de pesquisas. Por exemplo, no capítulo "O que sabemos sobre parcerias público-privadas na educação", do relatório do $\mathrm{BM}$ intitulado O papel e impacto das parcerias público-privadas na educação (Patrinos 
et al., 2009), este aponta para um quadro misto de evidências - em muitos casos, por exemplo, enquanto não é capaz de superar problemas de seleção de estudantes e escolas, segue fazendo fortes declarações sobre eficiência e efetividade do setor privado no fornecimento de educação.

Estruturalmente, o neoliberalismo não apenas se incorporou numa série de escalas - do local ao global -, sendo que a crise mundial de 2008 fez pouco para desalojar o neoliberalismo por um momento, mas também houve um aprofundamento das dependências dos países, tais como os Estados Unidos e o Reino Unido, da abertura de serviços como os novos padrões de valoração para o desenvolvimento econômico contínuo. É isso que Polanyi chama de "economic institutedness"(1992, p. 33) (em contraste com seu conceito de "embeddedness", que significa que os mercados estão sempre dentro de sociedades, e não fora delas). O que o autor quer dizer com isso é que os mercados são processos instituídos ao serem articulados por meio de instituições e estratégias legais e políticas. Desatar processos que constituíram e constitucionalizaram a educação enquanto um mercado torna-se particularmente difícil, uma vez que requer mais do que mudanças de ideias políticas. Desfazer formas completas de organização de uma economia da educação sem transtornos significativos no dia a dia torna-se cada vez mais problemático. Uma indústria especializada (cada vez mais corporativa), por exemplo, agora passa a crescer atrelada a PPPs, especialmente naquelas economias desenvolvidas que as levaram mais longe (como Austrália, Reino Unido, Estados Unidos). Essa indústria, que exporta cada vez mais sua especialidade globalmente, inclui um número em rápido crescimento de atores privados, de fundações, empresas especializadas em PPPs, empresas de consultoria global, bancos, consultores locais, think-tanks, websites direcionados, equipes de rápido retorno e escritórios de advocacia especializados, que cada vez mais atuam como fontes de autoridade voltadas para o mercado que "[...] estabelece as regras, normas e instituições que orientam o comportamento dos participantes e afetam as oportunidades disponíveis para os outros" (Cutler; Haufler; Porter, 1999, p. 4). Essa indústria especializada em PPPs é então parte de uma indústria emergente de serviços da educação, que inclui um número crescente de consultores da educação operando globalmente, organizações de administração educacional, bem como fundações educacionais e filantrópicas engajadas em moldar políticas e práticas na educação (Saltman, 2010). Analogamente, um pequeno grupo de empresas administrativas grandes, poderosas e globais tem também grandes interesses nas PPPs. Um pequeno número de grandes empresas (tais como KMPG, PricewaterhouseCoopers, Deloitte and Touche, Grant Thornton, Ernst \& Young, McKinsey, Hay Group) está atrelado a PPPs e também controla quase metade do mercado mundial de consultoria administrativa (Saint-Martin, 1998, p. 329; Hodge, 2009, p. 100). Essas grandes empresas têm expressivos portfólios na área da educação.

Por pura habilidade no desenvolvimento dos sistemas legais voltados às PPPs e a prática efetiva no campo em países que são referência, as empresas globais de consultoria, dado seu conhecimento superior de como progridem as PPPs, encontram poucos adversários. (Greve, 2010, p. 506) 
Saint-Martin argumenta que não são apenas os mecanismos do neoliberalismo para a "boa governança" que contribuem para esse aumento; é também a abertura de alguns governos para esse tipo de especialidade (conhecimento econômico/contabilidade) e a permeabilidade do setor para com especialistas de fora: “[...] há uma íntima relação entre o desenvolvimento de um certo campo do conhecimento social - no nosso caso a consultoria administrativa - e a abertura das instituições estatais para a utilização de tal conhecimento"(1998, p. 325). E é aqui que governos e agências de desenvolvimento, tais como o BM, a IFC, o Banco Asiático de Desenvolvimento (Asia Development Bank), juntamente com os consultores corporativos, têm executado um papel crucial na formatação das condições para o fornecimento da educação, enquanto constitucionalizam o liberalismo de mercado em políticas e estruturas de regulamentação entre os territórios dos estados nacionais. O termo "consultocracia" é usado para descrever o poder que têm os consultores ao informar o governo e assim moldar as políticas governamentais. Como percebe Hodge (2009, p. 99), a preocupação vocalizada por meio deste rótulo "[...] é a de que os interesses dos consultores administrativos de maximização de lucros podem tornar-se determinantes para as políticas 'gerencialistas"”. Levando em conta que esses consultores são, em alguns casos, também os advogados (Hogan Lovells Lee \& Lee, 2009) e auditores (Greve,2010) das PPPs, essas relações de consultoria levantam grandes preocupações a respeito de conflitos de interesses, transparência e responsabilização.

Há também um vasto crescimento de companhias globais da área de educação, variando entre consultores educacionais, como a Cambridge Education; organizações administrativas da educação (por exemplo, as charter schools em funcionamento nos Estados Unidos ou as "academias" no Reino Unido); corporações educacionais como Laureate, Cisco Systems, deVry, Bridgewater, Edison Schools; e grandes conglomerados que possuem maioria em ações de "negócios da educação", como a Apollo Global. Todas veem o setor educacional como crítico, oferecendo uma variedade de possibilidades de investimento em serviços da educação, contanto que as condições estejam alinhadas com a possibilidade de realização lucrativa (ver, por exemplo, Ball, 2007; Hentschke, Lechuga; Tierney, 2010; Saltman, 2010).

Como poderíamos avaliar o rápido crescimento entre atores privados e seus interesses em um setor como o da educação? O trabalho de Cutler sobre as implicações legais do atenuamento da fronteira entre as autoridades pública e privada é convincente. Ela não apenas argumenta, como Gill (2003), que direitos privilegiados de cidadania e representação são conferidos com capital corporativo, mas, na medida em que o Estado se despoja das atividades que tradicionalmente associamos ao setor público e de interesse público, podemos ver uma tendência ascendente entre as administrações dos negócios em nível nacional, regional e global por atores econômicos, e não estatais/políticos (Cutler; Haufler; Porter, 1999). Cutler chama essa ascensão de "autoridade privada", ou seja, quando um indivíduo ou uma organização tem maior poder de decisão sobre uma determinada questão (p. 5). No setor educacional, o fato de o Estado ceder o poder de tomar decisões (de que maneira enquadrar as bases operacionais e de regulamentação da atividade educacional, por exemplo) para atores econômicos (como corporações educacionais, firmas de consultoria, filantrópicas de risco), ou àqueles que fazem suas 
apostas e barganhas (como o BM, a IFC), representa uma virada da autoridade da esfera pública para a esfera privada, e do nacional para o supranacional. Isso gera implicações significativas para a educação, para a sociedade e para a democracia (Crouch, 2011).

Há, contudo, contradições na estratégia do BM para a privatização da educação - incluindo-se: o seu ventriloquismo entre políticas e evidências versus a sua insistência em evidências robustas e políticas baseadas em conhecimento; os projetos de privatização da IFC, em que esta insiste que são de auxílio aos mais pobres; no entanto, os mesmos pobres têm recursos financeiros limitados para gastar com a educação tida como commodity; que o lucro das empresas educacionais advenha de economias de escopo e escala voltados para a padronização, enquanto isso subestima as bases da competitividade que é dependente de inovação e criatividade; a consolidação e a expansão de atividades empresariais internacionais, que em troca subestimam a contribuição da educação para a coesão social em estados nacionais; pressões por flexibilidade no trabalho do professor, o que em troca gera diminuição do profissionalismo e aumento dos custos direcionados à vigilância e responsabilização dos professores; a transformação da educação em uma commodity, o que em troca gera debates em torno do caráter político e social do conhecimento e da educação; a administração da educação por meio de formas privadas (autoridade irresponsabilizável) versus a centralidade de alguma forma de democracia para garantir o contínuo poder e legitimidade do Estado.

\section{SOBRE O QUE PODE SER FEITO - CONCLUINDO}

Este artigo lançou-se a explorar e explicar a estranha não morte do neoliberalismo nas políticas e programações para a educação entre os grupos do BM. Ao estudarmos os engajamentos do BM no tempo, como estes se mostram articulados em relatórios-chave, políticas e projetos ao longo da última década, é possível traçar as maneiras como o BM tem continuado estrategicamente a reinventar e promover sua agenda, de modo que contribua para a institucionalização da lógica de livre mercado para dentro de estruturas políticas legais e sociais, por entre arquiteturas de regulamentação nacionais e globais.

A pergunta, então, sobre o que pode ser feito, acompanhou-me ao longo deste artigo. Acredito que em muitas de nossas avaliações da privatização da educação não desenvolvemos suficientemente uma abordagem analítica que conecte o estrutural ao estratégico e o local com as articulações multiescalares; as manobras fracassadas às reinvenções no tempo e no espaço; ou a "institutedness" de mercados com o real trabalho que os constrói. Esse é um projeto intelectual - mas não um que eu vejo como a principal reserva daqueles entre a academia. Antes, devemos usar o nosso espaço privilegiado como intelectuais orgânicos para que a esquerda gere insights para dentro do lugar altamente complexo da educação nas nossas sociedades e insista que a educação é política, porque se trata de chances e mudanças de vida. Ela é mais do que um direito humano, ou simplesmente um sistema pelo qual o conhecimento oficial é transmitido e adquirido. É também mais do que um bem público. É um espaço altamente disputado, de condição pública e potencialmente emancipatória, importante para o nosso futuro, mas cujo próprio poder de decisão acerca desses valores é questionado. 


\section{REFERÊNCIAS}

BALL, Stephen. Education plc: understanding private sector participation in public sector education. London and New York: Routledge, 2007.

Berger, Mark; Beeson, Mark. Lineages of liberalism and miracles of modernisation: the World Bank, the east asian trajectory and the international development debate. Third World Quarterly, v. 19, n. 3, p. 487-504, 1998.

Bonal, Xavier. Plus ça change... the World Bank global education policy and the post-Washington Consensus. International Studies in Sociology of Education, v. 12, n. 1, p. 3-22, 2002.

Bretton Woods Project. The World Bank and the International Finance Corporation: Bretton Woods Project input into the DfID multilateral review. London: Bretton Woods Project, 2010.

Crouch, Colin. The strange non-death of neoliberalism. Cambridge: Polity, 2011.

Cutler, A. Claire; Haufler, Virginia; Porter, Tony (1999). Private authority and international affairs. New York: State University of New York Press, 1999.

Gewirtz, Sharon; BAll, Stephen; Bowe, Richard. Markets, choice and equity in education. Basingstoke: Open University Press, 1995.

Gill, Stephen. Power and resistance in the New World Order. London: Palgrave, 2003.

Greve, Carsten. The global public-private partnership industry. In: Hodge, Graeme; Greve, Carsten; Boardman, Anthony (Eds.). International handbook on public-private partnerships. Cheltenham: Edward Elgar. 2010.

Hall, Stuart. The great moving right show. Marxism Today, jan. 1979.

Harrison, Graham. Administering market friendly growth? Liberal populism and the World Bank's involvement in administrative reform in sub-saharan Africa. Review of International Political Economy, v. 8, n. 3, p. 528-547, 2001.

. Economic faith, social project and a misreading of african society: the travails of neoliberalism in Africa. Third World Quarterly, v. 26, n. 8, p. 1.303-1.320, 2005.

Harvey, David. A brief history of neoliberalism. Oxford University Press: Oxford, 2005. Hatcher, Richard. Privatization and sponsorship: the re-agenting of the school system in England. Journal of Education Policy, v. 21, n. 5, p. 599-619, 2006.

Hentsch ke, Guilbert; Lechuga, Vicent; Tierney, William (Eds.). For-profit colleges and universities. Virginia: Stylus, 2010.

Новsваwм, Eric. Age of extremes: the short twentieth century 1914-1991. London: Abacus, 1994.

Hodge, Graeme. Delivering performance improvements through public private partnerships: defining and evaluating a phenomenon. In: The Institute of Public administration (IPa). International Conference on Administrative Development: Towards Excellence in Public Sector. 2009. Saudi Arabia, 1-4 nov. 2009. 
; Greve, Carsten; Boardman, Anthony. Conclusions: public private partnerships - international experiences and future challenges. In: . (Eds.). International handbook on public-private partnerships. Cheltenham: Edward Elgar, 2010. Hogan Lovells Lee \& Lee. PPP Projects in the education sector: key principles. [online] 2009. Disponível em: <http://www.hoganlovells.de/files/Publication/bb9e9af9-213c4568-87c0-769e1c3e069a/Presentation/PublicationAttachment/94598918-0d93-4526a06b-86abc1d630fb/PPPprojectsintheeducationsector-keyprinciples.pdf $>$. Acesso em: 6 out. 2010.

ILoN, Lynn. Structural adjustment and education: adapting to a growing global market. International Journal of Education and Development, v. 14, n. 2, p. 95-108, 1994.

International Labour Organization (Ilo). A fair globalization: creating opportunities for all, the World Commission on the Social Dimensions of Globalization. Geneva: ILO, 2004.

Jones, Philip; Coleman, David. The united nations and education: multilateralism, development and globalisation. London and New York: Routledge, 2005.

. World Bank Financing of education: lending, learning and development. $2^{\mathrm{a}} \mathrm{ed}$. London and New York: Routledge, 2007.

Jessop, Bob. Imagined recoveries, recovered imaginaries: a cultural political economy perspective. Economy and Society (under review), july, 2011 (no prelo).

KLeEs, Steven. A quarter of a century of neoliberal thinking in education: misleading analyses and failed policies. Globalisation, Societies and Education, v. 6, n. 4, p. 311-348, 2008.

. World Bank education policy: new rhetoric, old ideology. International Journal of Educational Development, v. 22, p. 451-474, 2002.

Molnar, Alex. The commercial transformation of public education. Journal of Education Policy, v. 21, n. 5, pp. 621-40, 2006.

Newman, Janet. Modernising governance. London: Sage, 2001.

PATRINos, Harry Anthony et al. The role and impact of public-private partnerships in education. Washington: World Bank, 2009.

Peck, Jamie. Constructions of neoliberal reason. Oxford: Oxford University Press, 2010.

Polanyi, Karl. The economy as an instituted process. In: Granovetter, Mark; Swedberg, Richard (Eds.). The sociology of economic life. Boulder (CO): Westview Press, 1992.

Robertson, Susan L.; Bonal, Xavier; Dale, Roger. GATS and the education service industry. Comparative Education Revierw, v. 46, n. 4, p. 472-496, 2002.

.The new spatial politics of (re)bordering and (re)ordering the state-educationcitizen relation. International Review of Education, v. 57, n. 3-4, p. 277-297, 2011.

RoDrik, Dani. The globalization paradox: why markets, states and democracy can't co-exist. Oxford: Oxford University Press, 2011. 
Saint-Martin, Denis. The New managerialism and the policy influence of consultants in government: an historical-institutionalist analysis of Britain, Canada and France. Governance: International Journal of Policy and Administration, v. 11, n. 3, p. 319-356, 1998. Saltman, Kenneth. The gift of education: public education and venture philanthropy. New York: Palgrave, 2010.

SAmofF, Joel. Coping with crisis: austerity, adjustment and human resources. London/ New York: Cassell with UNESCO, 1994.

Sell, Susan. Cat and mouse: Forum Shifting in the Battle over Intellectual Property Enforcement. Paper presented at the American Political Science Association Meeting, sept. 3-6, 2009, Toronto.

Verger, Antoni. Framing and selling global education policy: the promotion of public-private partnerships for education in low-income contexts. Journal of Education Policy, 2012, (no prelo).

WADE, Robert Hunter. On the causes of increasing world poverty and inequality, or why the Matthew Effect Prevails. New Political Economy, v. 9, n. 2, p. 163-188, 2004.

Williamson, John. Democracy and the "Washington Consensus". World Development, n. 21, p. 1.329-1.336, 1993.

WoRld BANk. Education sector strategy. Washington: The World Bank Group, 1999.

. Learning for all: investing in people's knowledge and skills to promote development, World Bank Group Education Strategy 2020. Washington: The World Bank Group, 2011.

. New World, New World Banking Group: (I) post crisis directions. Washington: The World Bank Group, 2010.

.PPPs: a toolkit. Washington: The World Bank Group, 2001.

\section{SOBRE A AUTORA}

Susan L. Robertson é doutora em educação pela universidade de Calgary, Canadá. Professora da Universidade de Bristol, Reino Unido.

E-mail: s.l.robertson@bristol.co.uk

Recebido em dezembro de 2011 Aprovado em maio de 2012 


\section{SUSAN L. ROBERTSON}

\section{A estranha não morte da privatização neoliberal na Estratégia 2020 para a educação do Banco Mundial}

O artigo trata da estranha "não morte do neoliberalismo" (Crouch, 2011), referencial ideológico que permanece entre as prioridades das políticas do setor educacional do Banco Mundial (BM). Analisam-se, para exemplificar esse fenômeno, dois relatórios da estratégia do setor educacional, Education Sector Strategy 1999 (Banco Mundial, 1999) e Education Strategy 2020 (Banco Mundial, 2011), usados para orientar as operações do $\mathrm{BM}$ na área da educação. Focam-se particularmente as maneiras como um setor privado expandido, juntamente com a Corporação Financeira Internacional (International Finance Corporation - IFC) (o braço investidor do setor privado do BM), é promovido como detentor do conhecimento e da capacidade para atuar num papel mais central na educação enquanto um "mercado emergente". Dessa forma, o artigo centra sua crítica na questão das parcerias público-privadas (PPPs), refletindo sobre o neoliberalismo enquanto projeto político e sobre o paradoxo de seus visíveis fracassos, ao menos por ora, parecerem inspirar rodadas mais avançadas de engenhosidade neoliberal no setor educacional.

Palavras-chave: neoliberalismo; Banco Mundial; educação; parceria público-privada; privatização.

\section{The strange non-death of neoliberal privatisation in the World Bank's Education strategy 2020}

This paper discusses the strange "non-death of neo-liberalism" (Crouch, 2011) in the Bank's education sector policy priorities. A key point of entry will be the two education sector strategy reports, Education Sector Strategy 1999 (World Bank, 1999) and the Education Strategy 2020 (World Bank, 2011), to guide the Bank's education operations. The article focuses particularly on the ways in which an expanded private sector, together with the International Finance Corporation (the Bank's private sector investment arm) are promoted 
as having the knowledge, and capacity, to play a more central role in education as "an emerging market".Thus, the paper criticizes public private partnerships (PPPs), reflecting on neoliberalism as a political project, and on the apparent paradox that, for the moment at least, its manifest failures seem to animate further rounds of neoliberal ingenuity in the education sector.

Keywords: neoliberalism; World Bank; education; PPP; privatization.

\section{La extraña no-muerte de la privatización neoliberal en la Estrategia 2020 para la educación del Banco Mundial}

Este artículo hace referencia a la extraña "no-muerte del neoliberalismo" (Crouch, 2011), marco ideológico que se encuentra entre las prioridades de las políticas del sector de educación del Banco Mundial. Se analizan, para ejemplificar este fenómeno, dos informes de la estrategia del sector de educación: Education Sector Strategy 1999 (Banco Mundial, 1999) $y$ Education Strategy 2020 (Banco Mundial, 2011), usados para orientar las operaciones del Banco Mundial en el área de la educación. Se focalizan particularmente las maneras como un sector privado expandido, juntamente con la Corporación Financiera Internacional (el brazo inversionista del sector privado del Banco), se promueve como el que detiene el conocimiento y la capacidad para actuar en un papel más central en la educación, en cuanto "mercado emergente". De esta forma, el articulo centraliza su crítica en la cuestión de las Sociedades Público-Privadas $(S P P s)$, reflexionando sobre el neoliberalismo, en calidad de proyecto politico, y sobre la paradoja de sus fracasos visibles que, al menos por ahora, parecen inspirar acciones más avanzadas de ingeniosidad neoliberal en el sector de la educación.

Palabras clave: neoliberalismo; banco mundial; educación; SPPs; privatización. 